\title{
Zum 100. Geburtstag von Prof. Dr. med. Eberhard Willich
}

1919 wurde das erste Ordinariat für Röntgenologie in Deutschland an der neu gegründeten Hamburgischen Universität geschaffen, auf das Prof. Albers-Schönberg berufen wurde. Er war nicht nur Erstbeschreiber der Marmorknochenkrankheit, es gelang ihm auch die erste Röntgendarstellung eines Kindes in utero.

Im gleichen Jahr wurde ein Pionier der europäischen Kinderradiologie, Prof. Dr. Eberhard Willich, in Stuttgart als ältester Sohn eines Offiziers geboren. Nach der Schulausbildung an verschiedenen humanistischen Gymnasien studierte er Medizin, legte 1943 das Staatsexamen in Berlin ab und promovierte im selben Jahr über die kongenitale Lungenzyste in Tübingen. Der 2. Weltkrieg bedingte den Einsatz als Truppenarzt und eine 4-jährige Gefangenschaft in der Sowjetunion. 1949 konnte er seine medizinische Weiterbildung wieder aufnehmen, die er 1956 in Pädiatrie an der Städtischen Kinderklinik Bremen und 1962 als Arzt für Radiologie am Zentral-Röntgeninstitut der Städtischen Krankenanstalten Bremen abschloss. Entscheidender Mentor für ihn war Prof. Dr. Lutz Schall, damaliger Direktor der Kinderklinik, dessen besondere Vorliebe, seit seiner röntgenologischen Weiterbildung in den 20er Jahren, der Kinderradiologie galt. Er beauftragte ihn mit dem Aufbau der Röntgenabteilung der Bremer Kinderklinik. Zusammen entwickelten sie 1962 ein Zusatzgerät für die Röntgenuntersuchung von Kindern, das Paidoskop (Fa. Koch und Sterzel KG, Röntgenwerk Essen), das an allen den DIN-Vorschriften entsprechenden Durchleuchtungsgeräten angebracht werden konnte. 1965 wurde er mit dem Preis und dem Stipendium der
Bremer Stiftung zur Förderung der Wissenschaften der Universität ausgezeichnet. Ab 1969 leitete er die Röntgenabteilung der Universitätskinderklinik Heidelberg, die er zu internationalem Ruf führte. 1970 erfolgte seine Habilitation mit dem Thema „Kardiafunktion im Kindesalter. Manometrische, kinematografische und pharmakoradiografische Untersuchungen“, gefördert von der DFG. 1973 erhielt er die C3-Professur, seit 1984 ist er emeritiert.

Sein Einsatz für die pädiatrische Radiologie bleibt beispielhaft:

In seiner 10-jährigen Tätigkeit als erster Vorsitzender der Gesellschaft für Pädiatrische Radiologie hat er die Voraussetzung für die Anerkennung dieses Teilgebiets geschaffen.

Er hat sich um die Verbindung zu den Kinderradiologinnen und -radiologen der Ostblockländer kontinuierlich bemüht und ist Ehrenmitglied der Polnischen und der Ungarischen Röntgengesellschaft.

In mehr als 300 Publikationen, Lehr- und Handbuchbeiträgen, Monografien und 3 Lehrbüchern hat er sich mit der Kinderradiologie wissenschaftlich auseinandergesetzt, wobei ihm Lehre und Fortbildung besonders am Herzen lagen.

Er war Mitherausgeber des Radiologen, in der Schriftleitung des Zentralblatts für Kinderheilkunde und im Editorial Board von Pediatric Radiology. Er ist Ehrenmitglied der European Society of Pediatric Radiology und der Gesellschaft für Pädiatrische Radiologie, an deren Entwicklung

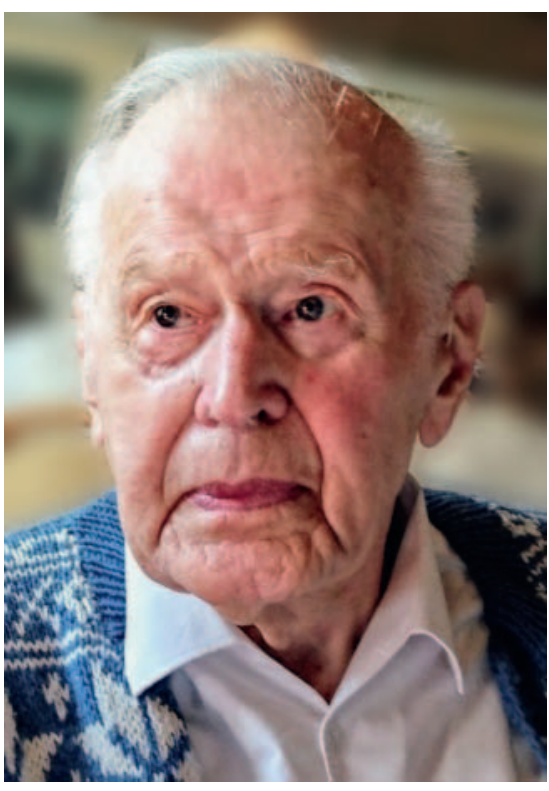

Prof. Dr. med. Eberhard Willich

er bis heute Anteil nimmt. Als bisher einziger deutscher Kinderradiologe wurde er mit der Ehrenmitgliedschaft der Deutschen Röntgengesellschaft geehrt.

Seine umfassende Bildung, die hohe Disziplin, seine Liebenswürdigkeit und Bescheidenheit und der hintergründige Humor machen seine Persönlichkeit aus.

Am 19. Februar ist sein 100. Geburtstag. Die Gesellschaft für Pädiatrische Radiologie gratuliert in tiefer Dankbarkeit.

Gabriele Benz-Bohm, Hans-Conrad Oppermann, Hans-Joachim Mentzel 